\title{
YIELD PERFORMANCE OF CORN UNDER HEAT STRESS: A COMPARISON OF HYBRID AND OPEN-POLLINATED SEEDS DURING A PERIOD OF TECHNOLOGICAL TRANSFORMATION, 1933-1955
}

\author{
Keith Meyers \\ Paul Rhode \\ Working Paper 27291 \\ http://www.nber.org/papers/w27291
NATIONAL BUREAU OF ECONOMIC RESEARCH
1050 Massachusetts Avenue
Cambridge, MA 02138

May 2020

We wish to thank Petra Moser and Michael Roberts for helpful suggestions and data. The views expressed herein are those of the authors and do not necessarily reflect the views of the National Bureau of Economic Research.

NBER working papers are circulated for discussion and comment purposes. They have not been peer-reviewed or been subject to the review by the NBER Board of Directors that accompanies official NBER publications.

(C) 2020 by Keith Meyers and Paul Rhode. All rights reserved. Short sections of text, not to exceed two paragraphs, may be quoted without explicit permission provided that full credit, including $(\odot$ notice, is given to the source. 
Yield Performance of Corn under Heat Stress: A Comparison of Hybrid and Open-Pollinated

Seeds during a Period of Technological Transformation, 1933-1955

Keith Meyers and Paul Rhode

NBER Working Paper No. 27291

May 2020

JEL No. N12,O3,Q16,Q55

\begin{abstract}
Starting in the 1930s, commercial hybrid corn seeds rapidly replaced the once predominant openpollinated varieties planted by farmers. By the mid-1950s almost all corn grown in the United States was of hybrid varieties. Observers have argued that the drought tolerant qualities of these hybrids were a major factor driving farmers' decisions regarding hybrid adoption, but there is little statistical evidence to substantiate this assertion. Hybrid seeds exhibited other attractive qualities, such as improved performance during prime weather conditions, resistance to wind damage, and increased suitability toward mechanized harvesting. Using historical evidence from Zvi Griliches's archival records, we reconstruct data on hybrid corn adoption and yields at a more disaggregated geographic level than previously available. We match these data with historical weather records to measure the extent to which hybrid seeds mediated the adverse effects of extreme heat. Our findings suggest that hybrid corns grown in Iowa from 1928 to 1942 did exhibit heat tolerance relative to open-pollinated varieties. This result is unique to Iowa as this reduced temperature sensitivity does not appear when comparing hybrid and open-pollinated grown in other states.
\end{abstract}

Keith Meyers

D-IAS, Danish Institute for Advanced Study

University of Southern Denmark (SDU)

Campusvej 55

5230 Odense M, Denmark

meyersk@nber.org

Paul Rhode

Economics Department

University of Michigan

205 Lorch Hall

611 Tappan St.

Ann Arbor, MI 48109-1220

and NBER

pwrhode@umich.edu 


\section{Introduction}

The advent of commercially viable hybrid corn seeds in the 1930s preceded a rapid rise in U.S. corn yields over the rest of the $20^{\text {th }}$ century. This technology rapidly spread and quickly replaced the once predominant open-pollinated seed varieties grown in the United States. Zvi Griliches (1957) path-breaking work used the example of hybrid corn seeds to explain patterns in technological diffusion. Griliches posited that hybrid seeds had a fixed productivity advantage over open-pollinated seeds and increased the potential yield ceiling of corns. Hybrid corn spread first where initially (openpollinated) yields were higher. Other observers including Culver and Hyde (2001) and Sutch (2008, 2011) claim that hybrid corn seeds performed better relative to open-pollinated seeds principally during conditions of drought. Academic research, however, has not determined to what extent hybrid seeds mitigated the effects of drought and heat stress (temperatures generally associated with reductions in corn yields and drought-like conditions). ${ }^{3}$

The work of economic historians entails the development and re-discovery of novel data sources. Such archival resources contain reams of informative records with granular details that are not available in official digitally curated publications. Through archival work economic historians can answer otherwise unanswerable questions. In our efforts to understand the hybrid diffusion story we have located, digitized, and organized a treasure trove of historical unpublished manuscripts reporting on the hybrid corn diffusion and performance at a more granular geographic level than is available in U.S. Department of Agriculture (USDA) publications. Using unpublished documents contained in Zvi Griliches’s personal manuscripts and field trial data buried in obscure Iowa experimental station reports, we construct a panel of hybrid and open-pollinated corn yields. With

\footnotetext{
${ }^{3}$ For corn daily temperature averages in excess of 29 degrees Centigrade are associated with reductions in corn yields (Schlenker and Roberts 2009, Schauberger et al. 2017). Extreme temperature shocks are often strong proxies for drought like conditions. We also use drought measures as reported in the Palmer Drought Severity Index (PDSI) as an alternative measure of weather stress.
} 
these records we can ascertain whether or not hybrid seeds exhibited drought tolerance or if Griliches's assumption that hybrid seeds increased only the overall yield potential of corn were correct.

Understanding the relative performance of hybrid versus open pollinated corn seeds during periods of drought informs our understanding of the mechanisms driving the diffusion of the new technology. The Pioneer Hi-bred Company introduced the first successful commercial hybrid corn seeds in the early 1930s during a period of extreme farm distress, historically low commodity prices, and adverse weather conditions. While hybrid seeds cost two to three times more than their openpollinated counterparts, these new hybrid seeds rapidly replaced open-pollinated corns. If hybrid corns exhibited drought tolerance, then those traits could potentially explain the rapid diffusion of hybrid seed technology in response to the distress caused by the Dust Bowl droughts of the 1930s. Contemporary observers have argued that the drought resistant characteristics of hybrid seed technology and farmers' experiences with the Dust Bowl in the 1930s accelerated hybrid adoption (Dowell and Jesness 1939; Crabb, 1947).

Past research studying hybrid corn adoption starts with the path-breaking work of Zvi Griliches, (1957; 1958; 1960; 1980). Griliches’s analyses posited that profitability of the new seed technology, as captured by expected yield improvements, drove adoption. Even though hybrid seeds diffused across the Cornbelt and Great Plains during a period of extreme drought, Griliches does not investigate the effect of weather on adoption. In his preferred specification, Griliches assumed that the new hybrids were superior to the existing open-pollinated varieties by a multiple that did not vary significantly, over time, across regions, or by weather conditions.

More recent research contests Griliches’s account and suggests that drought shocks in 1934 and 1936 accelerated hybrid adoption (Culver and Hyde, 2001; Sutch, 2008, 2011). Sutch notes 
hybrid seed remained relatively expensive during the 1930s -- a period of historically low commodity prices -- and that the geographic pattern of the take-off of hybrid corn diffusion shows a dependence on local weather conditions. Narrative evidence adds further support. To cite one example, a New York Times headline read in 1940: "50\% of Corn Crop in Hybrid Species... Agricultural Marketing Service Lays its Popularity to Drought Resistance."4 Indeed, Sutch (2008, 2011) highlights the USDA's role in promoting adoption of hybrid seed technology and argues that hybrid corn seed's tolerance to drought conditions made the technology more salient for farmers. ${ }^{5}$ The economic stress of the Great Depression and extreme droughts of the 1930s eroded the wealth of farmers. One would expect slower hybrid adoption under such circumstances. Richard Hornbeck’s (2012) study of the Dust Bowl finds that many of the adaptive responses to the Dust Bowl were relatively slow. In comparison, from 1931 onward U.S. farmers rapidly adopted hybrid corn and these varieties eventually completely replaced the once dominant open-pollinated varieties. This switch towards hybrids may have mitigated some of the adverse effects of the Dust Bowl. Switching to hybrids was costly-- hybrid seed was far more expensive than open-pollinated seeds (Olmstead and Rhode, 2008). Nevertheless, the varieties produced by hybrid breeders promised beneficial qualities, included higher yields, shortened the time to maturity, stronger root systems, thicker stalks, disease resistance, as well as drought tolerance.

\footnotetext{
${ }^{4}$ New York Times, 10 Sept. 1940. The text noted the hybrid's advantages of both drought resistance and higher yields. ${ }^{5}$ Another critique of Griliches's account of hybrid diffusion came from Robert Dixon. Dixon (1980) observed that the diffusion process continued through the late 1950s and 1960s beyond the ceiling levels that Griliches employed. Dixon reanalyzed the extended annual state-level data, considering that diffusion to reach nearly 100 percent almost everywhere by the end of the period. Griliches’s modeling approach has also been criticized. David (2003) has cogently argued that it lacks micro-foundations; the logistic form is simply assumed, not derived from an underlying economic model.
} 


\section{Factors Driving Hybrid Adoption and the (Potential) Yield Advantage of Hybrid Corn Seeds}

The story of hybrid corn has been told many times (Crabb, 1947; Fitzgerald, 1990; Kloppenburg 1988; Olmstead and Rhode, 2008). For economists, the starting point is Griliches (1957). In his seminal article, Griliches (1957) analyzed this “invention of a way to invent” and maps estimated parameters of diffusion process into economic variables of supply and demand. He views the diffusion process as primarily a shift between two equilibria over time, rather than as a shift of equilibria. He fit logistic curves to annual diffusion data for states and crop reporting districts, reducing the differences across regions to differences in three parameters-- the origins, slopes, and ceilings. ${ }^{6}$ The origin represented the year (relative to 1940) when diffusion in an area crossed the 10 percent adoption threshold. Griliches related the origin date to “availability” of hybrid seed, and more specifically to supply-side forces including the profitability of seed producers, the cost of innovation, and potential market density. He related the slope (or speed of diffusion) and the ceiling levels to demand-side forces, specifically to the profitability to farmers of using the new seed. Griliches found the estimated speed of adoption was rather uniform but declined as one moves away from the center of the Cornbelt. The origin date and ceiling level also declined with distance from the center.

Griliches (1957) argued the diffusion process could be interpreted in a way consistent with rational, long-run profit-seeking behavior by seed producers and farmers. He made no reference to adverse weather shocks or to the drought-resistance qualities of hybrid varieties. ${ }^{7}$ According to his preferred specification, hybrids promised a time- and region-invariant yield increase -- in the range

\footnotetext{
${ }^{6}$ The analysis covered 31 (out of 48) states, and 132 (out of 249) crop reporting districts in the period up to 1956. The USDA's Agricultural Marketing Service made available unpublished data for the crop reporting districts. Griliches restricted analysis to observations between 0.05 and 0.95 of his estimated ceiling level, $\mathrm{K}$. The ceiling was estimated in an admittedly ad hoc way by picking the $\mathrm{K}$ that makes the resulting diffusion curves plotted on logistic graph paper look linear.
} 
of 10-15 percent-- over existing open-pollinated varieties. He further argued that including the changing advantages of the new seed, the prices of corn output, or the prices of hybrid seed, would add "nothing of significance" to the explanation of the diffusion process. ${ }^{8}$

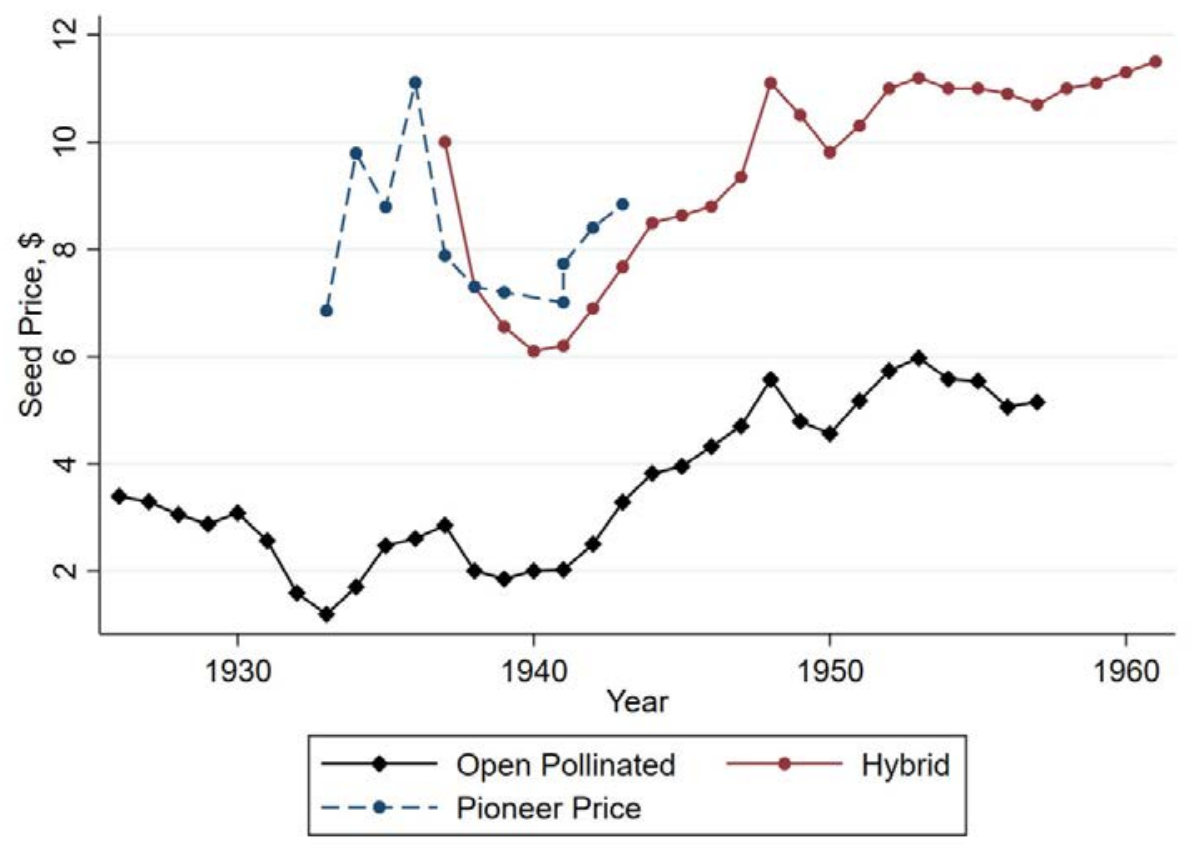

Figure 1. Nominal Prices (\$) of Open-Pollinated (OP) and Hybrid Corn Seeds. Sources: Pioneer Company Archives; USDA (1963). Prices paid by farmers for seed: spring season averages, 1926-1961: September 15 prices, 1949-1961 by states and United States. Statistical Bulletin No. 328. GPO: Washington, DC.

Griliches tabulated but did not use USDA data on the prices (per bushel) of hybrid and openpollinated seed by state (Box 59). ${ }^{9}$ He argued that the hybrid seed prices did not vary significantly across space and could be ignored in his analysis of the rate of diffusion (which was modeled as a transition between two equilibria). His treatment of hybrid seed prices is problematic for several reasons. The leading seed companies, especially in the early periods, possessed some market power

\footnotetext{
${ }^{8}$ It should be noted that in the mid-1950s Griliches did not have access to low cost computing power to conduct his econometric analysis. His records show calculations made by hand. This helps explain why he sought such parsimonious specification.

${ }^{9}$ Griliches relied on a USDA publication entitled “Seed Crops.” These are essentially the same as in USDA (1963).
} 
to set hybrid prices. The farmer's adoption decision did not rely on the hybrid corn price alone, but the hybrid seed price relative to other prices, for example, relative to the price of open-pollinated seed. In Figure 1, the average price of hybrid seed at the state level is approximately between two or three times greater than the average price of open-pollinated seed. Over the 1937-57 period, the coefficient of variation of the price of hybrid seed across states averaged approximately 10 percent. The coefficient of variations of the ratio of hybrid to open-pollinated seed was substantially higher, averaging 16 percent. Griliches also ignored changes over time. In the late 1930s, hybrid seed cost about 3.5 times as much as open-pollinated seed. By the mid-1950s, the ratio had fallen roughly in half, to about 1.8 times. Griliches tabulated but did not use state-level data on seeding rates (Box 59). ${ }^{10}$ Again, he argued the cross-state variation was negligible. The coefficient of variation of seeding rates in bushels per acre was around 18.7 percent.

The path-breaking work of Griliches inspired a vigorous scholarly response (see Skinner and Staiger 2007). Ryan and Gross (1943; 1950) had conducted an earlier study of how Iowa farmers learned about hybrid technologies and how peer effects influenced their adoption decisions. They found that younger and more educated farmers adopted hybrids more readily than older or less educated farmers. They also highlighted the importance of drought conditions on adoption. In a series of papers, fellow rural sociologists debated with Griliches about the forces driving diffusion (Skinner and Staiger 2007, 254). Everett Rogers (2010) observed that Griliches abstracted from the contagionlike learning effects that are commonly used to justify the logistic form.

Richard Sutch (2008; 2011) revisited the early diffusion of hybrid corn, emphasizing the role of adverse weather shocks. Sutch (2008) argued that marketing campaigns and drought stresses (and the 1936 drought in particular) caused farmers to make the costly switch from open-pollinated to

\footnotetext{
10 These data were based on USDA, Agricultural Statistics, 1945, 1949, 1950.
} 
hybrid corns. The use of commercial hybrid seed reduced the self-sufficiency of farmers at a time of severe market stress, plausibly increasing risk. Sutch asserted that the early hybrid varieties were not inherently superior to available open-pollinated seeds and that farmers were rightly slow to adopt the expensive seeds in the late-1920s and early-1930s. Sutch (2008) wrote: "During the Depression hybrid seed was selling in Iowa for $\$ 6.00$ a bushel. Since a bushel of seed would plant two acres, a farmer would have to expect a financial gain of $\$ 3.00$ an acre to be tempted to pay full price. Expecting no more than 32 cents per bushel for the crop when sold, the advantage of hybrid seed would have had to approach 9 bushels per acre, not the 4-6 seen in the Iowa field tests."11

Sutch (2008) argued the adverse weather shocks of the mid-1930s, in combination with an intense USDA propaganda campaign, convinced Midwestern farmers to adopt the new seed. He noted the conflict of interest that hybrid pioneer Henry A. Wallace faced serving as USDA Secretary while retaining ownership of Pioneer Hybrid. ${ }^{12}$ Other observers in the 1930s, including the Chicago Tribune, were even more critical, arguing the yield-enhancing seed increased crop output at the very time that federal farm programs, run by Wallace, sought to reduce output through acreage restrictions.

Narrative evidence suggests farmers readily noticed that hybrid corn coped with the dry conditions better than open-pollinated corn planted nearby. As one farmer put it, in these very bad years, the hybrid corn was the last to die (Urban, 1975). Singling out the 1936 Dust Bowl drought, Sutch (2011) performed an analysis of hybrid diffusion on state-level data in the Cornbelt in the 1930s and argued that the 1936 drought hastened the adoption of hybrids through learning effects. Sutch was hampered by the lack of comprehensive geographically decentralized data. He was able to

\footnotetext{
${ }^{11}$ Sutch (2008) noted commodity prices were low and that seed was expensive. His analysis did not note that seed prices were endogenous, set according to market conditions. Nor did he address the subsidies hybrid seed producers gave farmers to adopt hybrids. One strategy used by seed sellers used to promote adoption was to initially offer farmers enough hybrid seed to plant half a field and take payment as the difference in yields at the end of the growing season. ${ }^{12}$ Pioneer was one of the leading commercial seed companies; other leadings hybrid producers at the time included DeKalb, Funk Farms, and Pfister.
} 
identify records on hybrid and open-pollinated seed productivity only from Iowa. With our new data (or more accurately, newly recovered old data), we seek to address these issues afresh and study hybrid performance from the late 1920s through the 1950s. ${ }^{13}$ Combining our data sources together allows us to construct a panel of hybrid corn yields, open-pollinated yields, yield differences, hybrid adoption rates, temperature exposure, and precipitation at the Crop Reporting District and Year Level for the regions where hybrid seeds first diffused. ${ }^{14}$

\section{Building our new Panel Data Set}

\section{Data on Hybrid Corn Adoption}

The hybrid corn adoption data used in this research project come from unpublished USDA data and notes contained in Zvi Griliches’s archival collection held at the Special Collections Library at Harvard University. ${ }^{15}$ These data, on the percentage of maize acreage planted in hybrid seed, are available at the level of Crop Reporting District (CRD). These detailed records-- drawn from a grid of roughly nine entries per state-- are based on unpublished data from the USDA's Agricultural Marketing Service. We have recovered these series for use for the first time since the 1950s. Many previous researchers had to rely on the USDA's state-level data from Agricultural Statistics.

The CRD diffusion data were compiled from a set of hand-written spreadsheets for the 19441955 period (Box 58), from typed sheets for all the CRDs in United States in 1959 (Box 60) and for Ohio CRDs for the 1935-1954 period (Box 58), and from very carefully marked diffusion graphs drawn by Griliches's own hand (Box 58). The graphs indicate the annual rate of diffusion by crop

\footnotetext{
${ }^{13}$ We thank Richard Sutch for making us aware the CRD-level diffusion data were available in the Griliches archives.

${ }^{14}$ Crop Reporting Districts are relatively equivalent to contemporary Agricultural Statistics Districts.

${ }^{15}$ Papers of Zvi Griliches, ca. 1930-2000. Collection Identifier: HUGFP 153. Harvard Library. We thank Diane Griliches for allowing access to these materials. We have also sought data at the USDA and AAA collections at the National Archives and at the National Agricultural Library.
} 
reporting district for each state on a 100-point (or finer) scale covering the period from first diffusion to $1954 / 55$. The numbers derived from the graphs match exactly those from available non-graphical sources. ${ }^{16}$

The adoption data allow us to define the region of interest for this study. Figure 2 visualizes how hybrid corn rapidly diffused across the U.S. Corn Belt and United States in the years following its initial introduction.

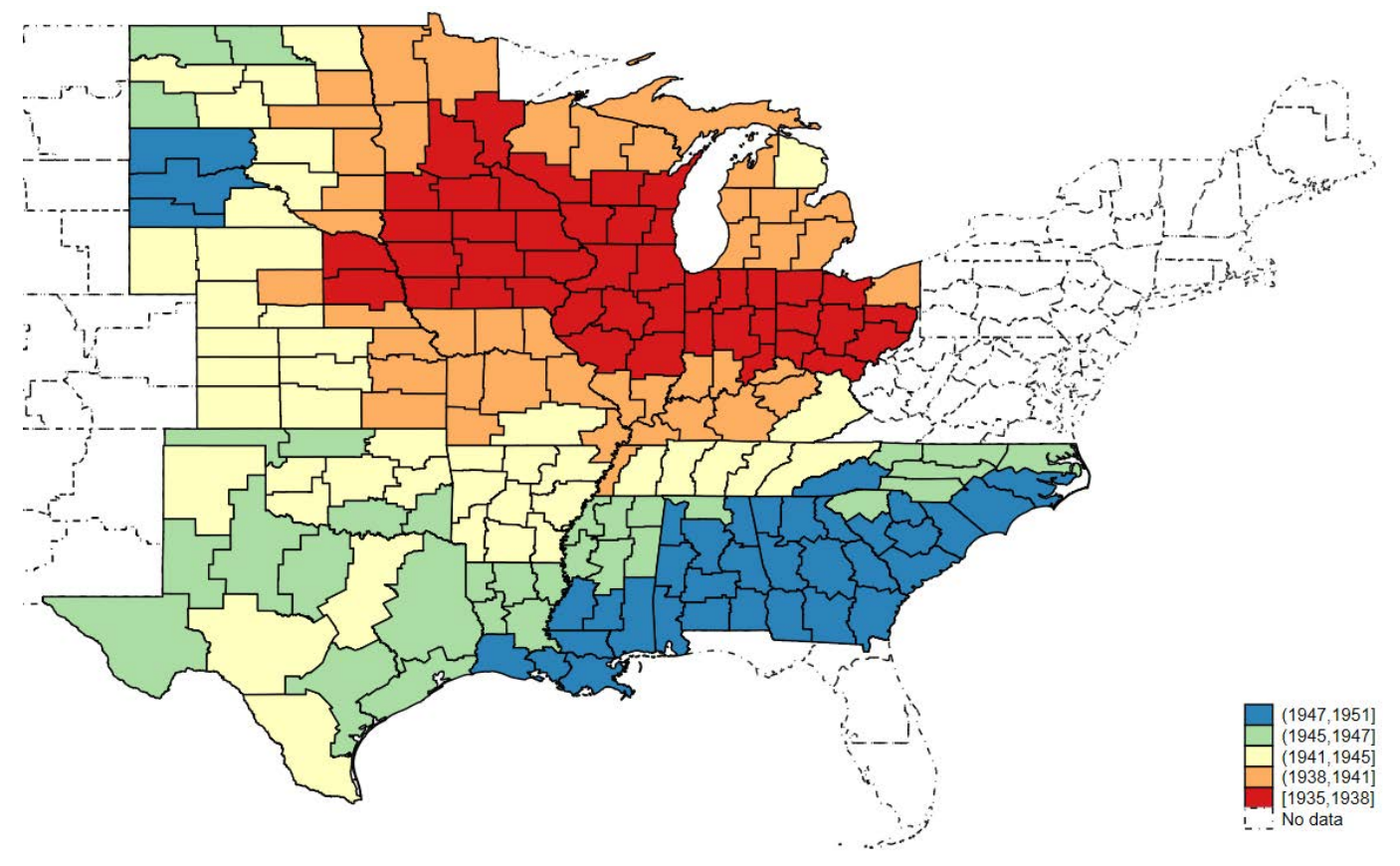

Figure 2. Crop Reporting District Map, Years When Hybrid Corns Exceed 10\% of Planted Corn. Source: Compiled from Zvi Griliches’s Archival Records.

\footnotetext{
${ }^{16}$ We have data for the northeastern states from 1945 on. However, this data does not cover the period of early hybrid adoption in northeastern states. We are seeking to supplement these data but have not been successful in our search of other archival sources. Griliches did collect maps of CRD data from the Agricultural Adjustment Administration for the 1938-41 period (Box 57). The AAA data have more extensive geographic coverage than the AMS data that Griliches chiefly used. Where there is overlap, the differences are relatively minor.
} 


\section{Data on Yields of Hybrid and Open-Pollinated Corns}

The yield data used in this empirical inquiry come from two primary sources. The first source is the data from experimental farm trials in Iowa from 1928 to 1942. These trials, which compared the relative performance of hybrid seeds to open-pollinated seeds, are reported in Zuber and Robinson (1941, 1942). These were the sources that Sutch investigated. ${ }^{17}$

The second source of information on yields is unpublished data held in the Griliches archives. Griliches collected voluminous data on the differential yields achieved by hybrid seed relative to open-pollinated seed. The data include the results of state yield trials and AAA surveys, as well as some yield data are at the sub-state level (Boxes 57, 60). ${ }^{18}$ The CRD data that Griliches actually used in his analysis were derived from AMS studies of "identicals," covering the period from 1939 on (Box 59). For early adopting states such as Iowa and Illinois, the series are short because little openpollinated seed was grown after the mid-1940s. Griliches used the AMS series chiefly in summary form. Note these data do not allow direct measurement of the effects of the weather shocks (e.g. droughts) of the mid-1930s. But the Iowa experimental trial yield data do.

Thus, Griliches’s archival records provide two measures for comparing hybrid and open pollinated yield differences. For some CRDs, average hybrid and open pollinated corn yields are available for selected years between 1937 to 1941. Figure 3 presents the regions these data cover and the differences between hybrid and open-pollinated yields by quartile.

\footnotetext{
${ }^{17}$ Sutch (2011) described ratios from Iowa Corn Yield Tests as representing all varieties tested. But the data are in fact for section varieties, the subset of varieties entered into tests in all three districts in a section. Records from Iowa reports average yield for all and section varieties for 1928 to 1932 ratios for all and the section subset are reported. The average hybrid to open-pollinated yield ratio was 1.1069 for all varieties entered but 1.095 for section varieties. A further issue with the test data in the location of the test districts and trial locations changes (marginally) over time. How these inconsistencies affect the comparison is unclear, a priori.

18 The sub-state regions covered do not always translate directly into CRDs.
} 


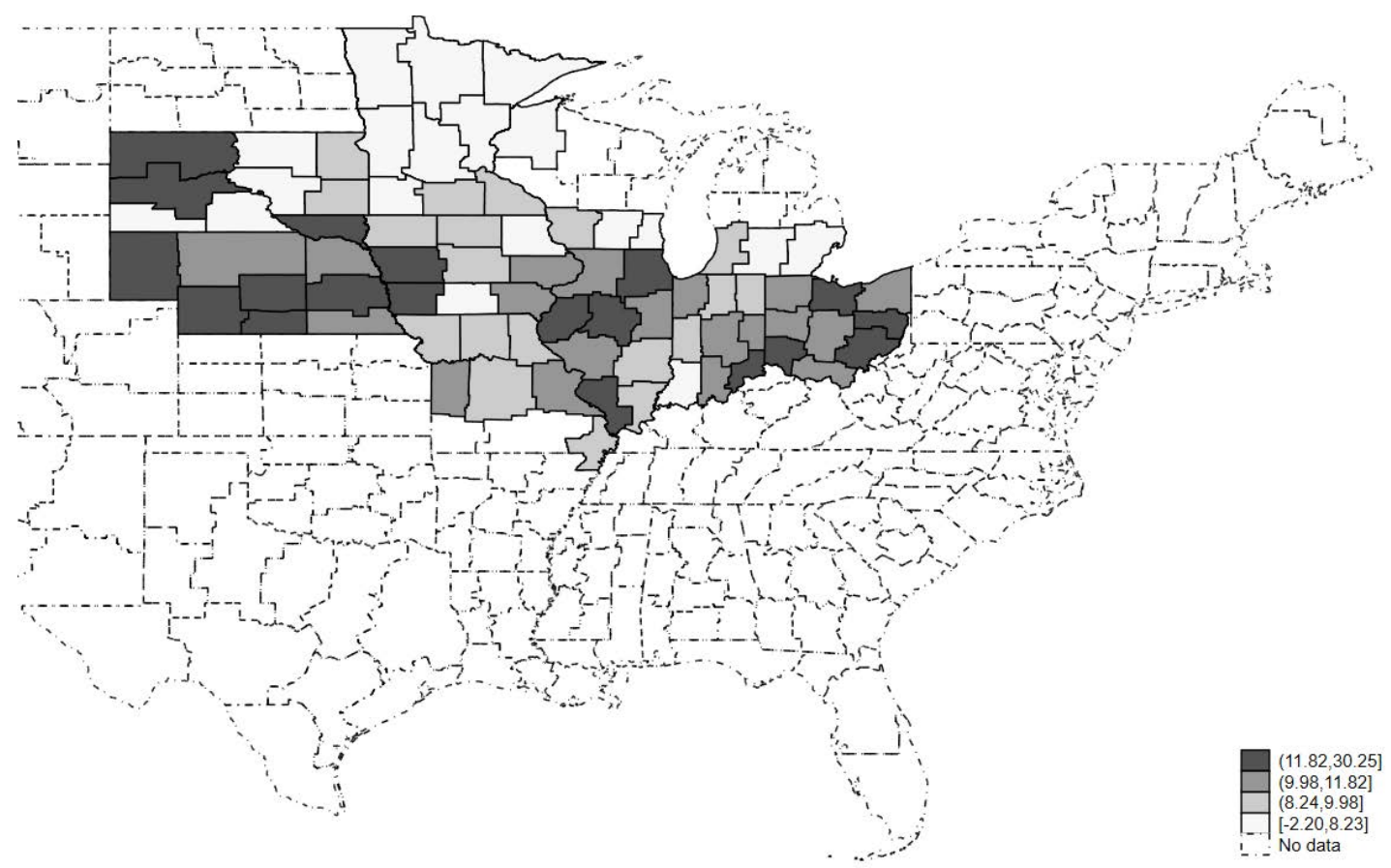

Figure 3. Average Hybrid Minus Average Open-Pollinated Corn Yield per Acre, quartiles, 1937-1941. Source: Griliches’s Archival Records.

An alternative measure for the difference between hybrid and open-pollinated yields comes from yield “identicals.” These are average differences in hybrid and open-pollinated corn seeds grown on the same farm within an CRD. These “identicals” are more consistently documented in Griliches’s archival records. The identical data are reported from 1939 to 1953 and have broader geographic coverage than the alternative yield data and are presented in Figure 4. With both the seed type yield specific data and "identicals" data there is a broad geographic coverage. The tradeoff with these data is they cover a time period almost a decade after hybrids had initially entered the market. 


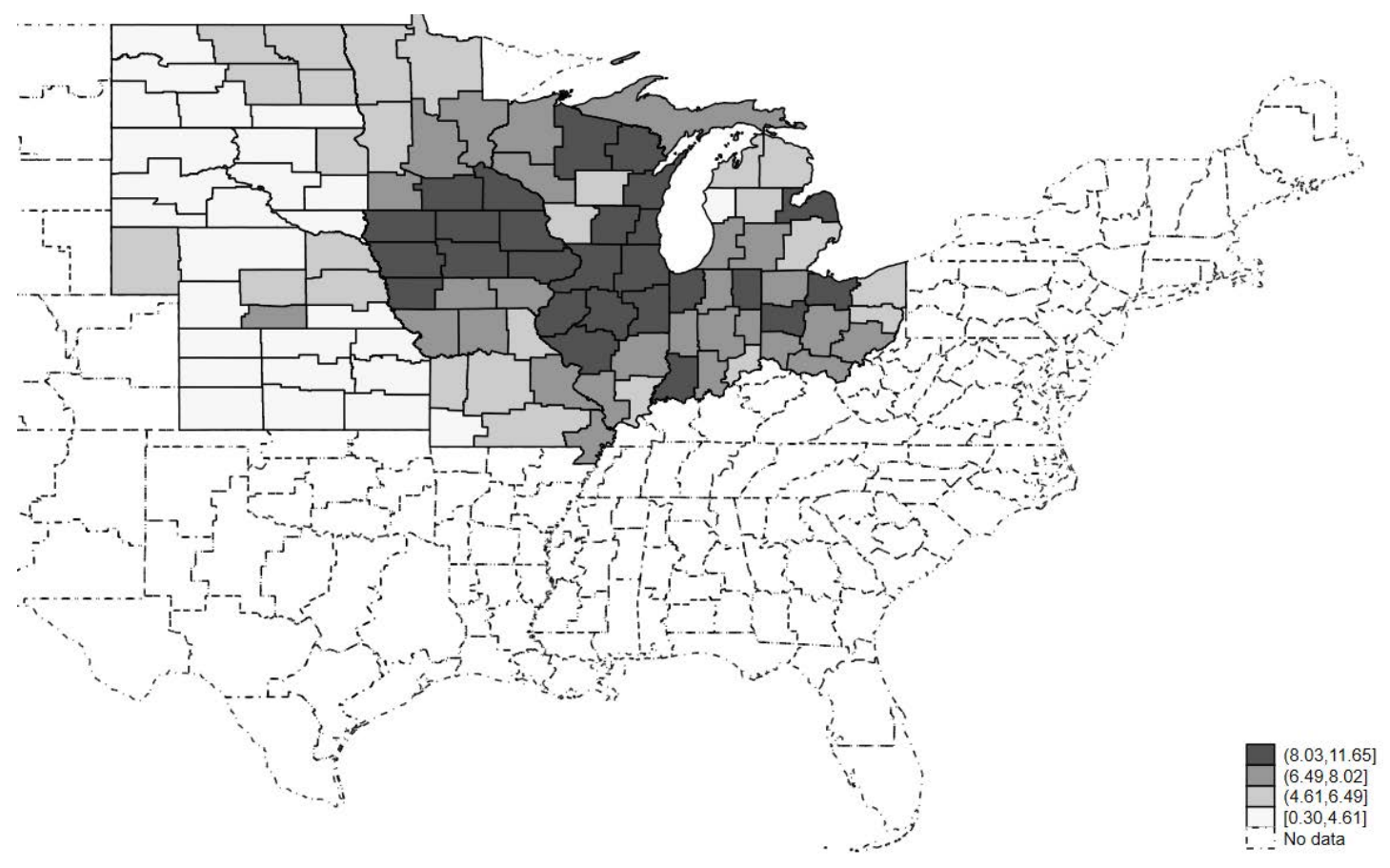

Figure 4. “Yield Identicals” per Acre, quartiles, 1939-1953. Source: Griliches’s Archival Records.

The rediscovery and rescue of the yield data, separating open pollinated and hybrid yields by crop reporting district, again demonstrate the value of archival research. Zvi Griliches was a preeminent researcher who collected and analyzed the pertinent evidence relevant to his study. He knew the importance of making direct comparisons of the yields of corn varieties under comparable settings, at the same time and in the same place. He collected data from experiment station trials and real-world production of identical farms. In his model, the yield difference drove adoption and hence Griliches sought independent measures of the gap.

\section{Data on Weather}

The weather data used in this study also come from two sources. The first is the Palmer Drought Severity Index (PDSI) derived from the Global Historic Climatology Network (Menne et. 
al. 2012.) The second source is the measurement of temperature and precipitation from Wolfram Schlenker's Detailed Daily Weather Data for the Contiguous United States. ${ }^{19}$

We use the Palmer Drought Severity Index to measure the effect of drought on hybrid and open-pollinated seed performance. The index is normalized around zero with values greater than zero associated with abnormally wet conditions for a specific region and values less than zero associated with abnormally dry conditions for a specific region. Values on the index between -1 and -2 denote mild drought conditions, values between -2 and -3 denote moderate drought conditions, and values less than -3 denote extreme drought conditions.

Extreme deviations in temperature are also often correlated with drought shocks. The second measure of weather stress used in our analysis is temperature and precipitation data derived from gridded weather data. These data were compiled and provided by Wolfram Schlenker (Columbia University) and Michael Roberts (University of Hawaii). The data are based on the PRISM weather dataset and is an updated version used in Schlenker and Roberts (2009). The raw data consists of daily minimum and maximum temperatures as well as total precipitation on a 2.5 by 2.5 mile grid of the continental United States. For each CRD, we use this gridded data to calculate the average daily minimum and maximum daily temperature along with daily total precipitation. We then construct growing degree days in accordance to agronomically observed heat sensitivity in corn yields, heat in excess of 29 degrees Centigrade (Schlenker and Roberts 2009, Schauberger et al. 2017). For each growing season, defined as lasting from April 1 to September 30, we calculated the total number of Moderate Growing Degree Days and Extreme Growing Degree Days.

1) $G D D=\left\{\begin{array}{cl}\frac{T_{\text {max }}-T_{\min }}{2}-T_{\text {base }} & \text { if } \frac{T_{\max }-T_{\min }}{2}>T_{\text {base }} \\ 0 & \text { if } \frac{T_{\max }-T_{\min }}{2} \leq T_{\text {base }}\end{array}\right.$

${ }^{19}$ We thank Michael Roberts for recommending that we use this source. 
Equation 1 defines a Growing Degree Day, GDD, as the average daily temperature calculated between the daily maximum temperature, $T_{\max }$, and daily minimum temperature, $T_{\min }$, minus some base temperature, $T_{\text {base. }}$ A Growing Degree Day measures the amount of heat exposure crops receive during a specific day and takes a value of zero for days below $T_{\text {base. }}$ Following the example of Schlenker and Roberts (2009), we differentiate between two measures of heat exposure for corn for each CRD for each year from 1920 to 1955 using GDD. We first sum up the number of GDD between 10 and 29 degrees Centigrade during the growing season as Moderate Growing Degree Days. This calculation assumes a base temperature of 10 degrees Centigrade. We sum days with average temperatures in excess of 29 degrees Centigrade as Extreme Growing Degree Days (and assume a base temperature of 29 degrees in this calculation). In addition to these heat measures, we also total the amount of precipitation during the growing season.

\section{Empirical Analysis of Our Panel Dataset}

Summary Statistics

Tables 1 and 2 describe the two unbalanced samples constructed for the analysis. In the Hybrid and Open-Pollinated Yields sample, most data are for the years 1939 to 1941 and does coincide with the end of the Dust Bowl drought waves. The yield identical data ranges from 1939 to 1953, has broader geographic coverage, and more variability in its measures of heat exposure and precipitation. The difference between hybrid corn and open-pollinated yields is on average 10.8 bushels of corn per acre. The yield identical finds a smaller difference of 6 bushels per acre for corns grown on the same farm.

Table 3 summarizes the Iowa experimental trial data from 1928 to 1942. The ratio of hybrid corn yields to open pollinated yields ranges from 97.4 to 153.4 and is on average 114.3. These data 
suggest that hybrid corn seeds outperformed open-pollinated corns by 14.3\% between 1926 and 1941 . This average is consistent with Griliches’s claims. ${ }^{20}$

\section{Empirical Method and Results}

To assess the relationship between drought and yield performance of hybrid and openpollinated corns we run the following regression specification:

1) $y_{i t}=\theta_{1} M D+\theta_{2} E D_{i t}+\alpha_{i}+\gamma_{t}+\varepsilon_{i t}$

The variable $y_{i t}$ denotes the natural log of the corn yields, yield difference, or yield identical in CRD $i$ in year $t$. In the Iowa trials data, $y_{i t}$, denotes the ratio of hybrid yields divided by open-pollinated yields. These outcomes are regressed on moderate and extreme drought indicator variables constructed from the PDSI, $M D_{i t}$ and $E D_{i t}$. We construct these drought indicators from the average PDSI over the growing season (April to September). Time invariant effects specific to each CRD are controlled for using CRD fixed effects, $\alpha_{i}$, and a quadratic time trend, $\gamma_{t}$, controls for potential underlying trends, such as concurrent changes in technology, shared across CRDs. Heteroskedastic standard errors, $\varepsilon_{i t}$, are clustered at the state (or CRD) level to account for potential correlation in the errors shared across CRDs from the same state.

To assess the effects of heat exposure on the yield performance of hybrid and open-pollinated corns we run the following linear regression specification:

2) $y_{i t}=\theta_{1} M G D D_{i t}+\theta_{2} E G D D_{i t}+\delta_{1} \operatorname{Prec}_{i t}+\delta_{2} \operatorname{Prec}^{2}+\alpha_{i}+\gamma_{t}+\varepsilon_{i t}$

The specification using growing degree days follows the predominant paradigm used in the agricultural economics literature. The outcomes of interest are regressed on moderate and extreme

\footnotetext{
${ }^{20}$ As Sutch (2011) notes, Griliches did not fully credit the yield gaps reports in the Iowa Corn Yield Test data because the farmers engaged in the test program were likely not representative of the farm population and achieved yields substantially higher than those commonly prevailing.
} 
degree days, $M G D D_{i t}$ and $E G D D_{i t}$. Annual growing season precipitation, Prec $_{i t}$, and the squared value of precipitation measure the effects rainfall has upon corn yields.

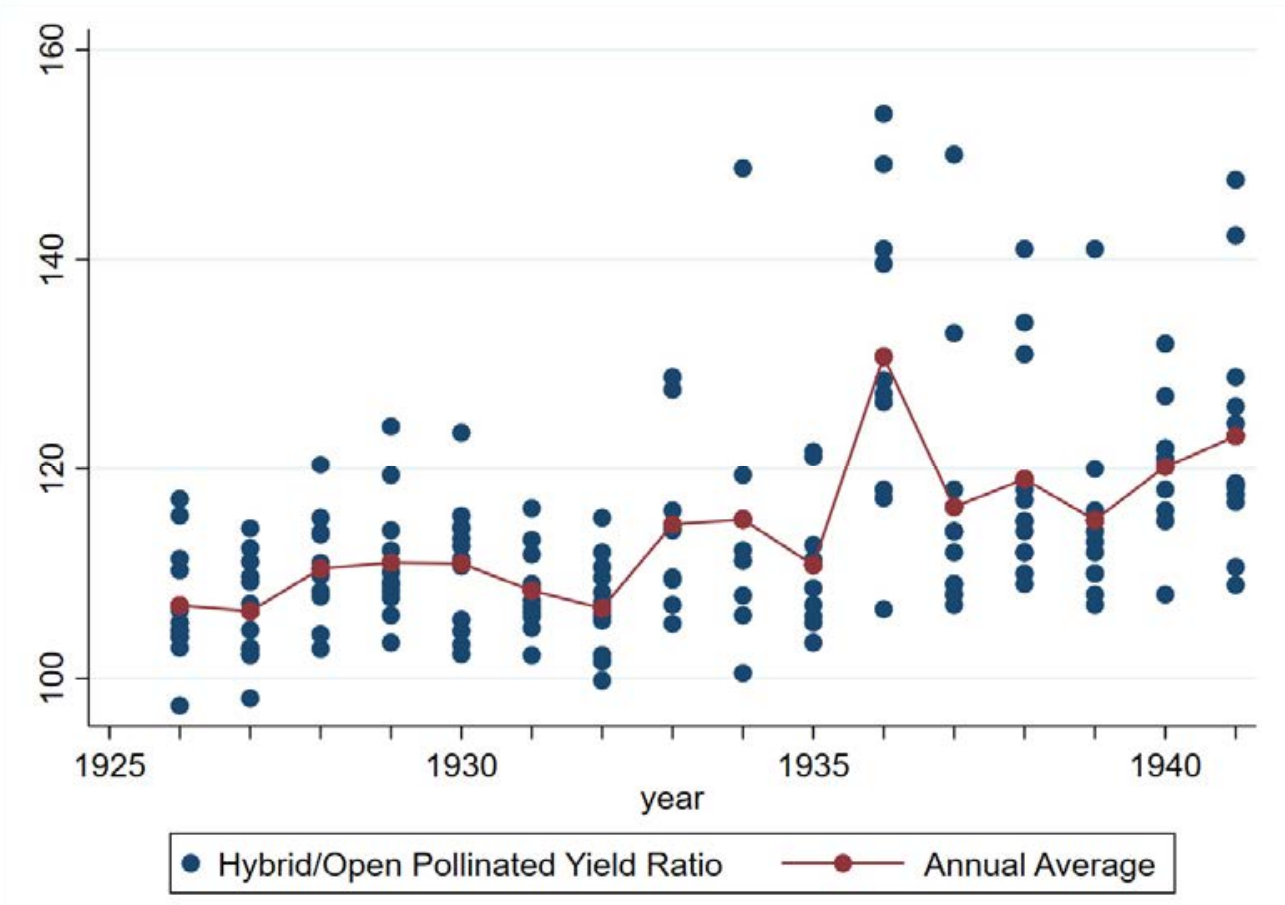

Figure 5. Hybrid to Open-Pollinated Corn Yield Ratios, Iowa Trials Data, 1926-1941. Source: Authors’ tabulation

Iowa Experimental Farm Results, 1926 to 1942

Much of the foundational work developing commercial hybrid corn seeds occurred in Iowa. We use experimental farm data from Zuber and Robinson (1941;1942) to study the relationship between heat stress and the performance of hybrid corns relative to open-pollinated corns. The data from the Iowa corn yield tests allow us to study hybrid performance when commercial hybrids are introduced and novel. They also let us study hybrid performance during early waves of the Dust Bowl droughts. Figure 5 suggests that hybrid yield performance in Iowa was much greater in 1936, a year of extreme Dust Bowl drought, relative to open-pollinated seed lines. It appears the pattern in hybrid to open pollinated yield ratios start to shift upwards in 1936. Both the floor and average of 
the ratios also increases until 1942. The last year yields for open pollinated corns are reported in Iowa stations is 1942. This is because hybrid corn seed technology had come to dominate corn production in Iowa by that time.

In Table 4 we regress the Iowa yield ratio against the moderate and extreme drought indicator variables. Moderate drought does not seem to have a differential effect on the relative performance of hybrid seed corn relative to open pollinated corn. Both specification (1) and (2) find that extreme drought increases the relative performance of hybrids to open pollinated corns by 21.5 and 41.7 respectively. These increases are statistically significant at the 1\% level. In Table 5 we regress the Iowa yield ratio against the temperature and precipitation data. We find results that are consistent with Sutch’s (2011) arguments about the role drought played in diffusion. Specification (1) finds that moderate growing degree days decrease the relative performance of hybrids and the effect is statistically significant at the $1 \%$ level. A 100 unit increase in moderate growing degree days decreases the ratio by 2.3. The statistical significance of the negative effect of moderate growing degree days is sensitive to the choice of quadratic time trends or year fixed effects. The coefficients for extreme growing degree days show that the relative performance of hybrids increased during periods of extreme heat. In specification (1) a 100 unit increase in extreme growing degree days increases the ratio by 21.5 and by 41.7 in specification (2). In both specifications the coefficients are statistically significant at the $1 \%$ level. These results support that narrative accounts that hybrid corns performed much better than open pollinated corns during periods of drought. 


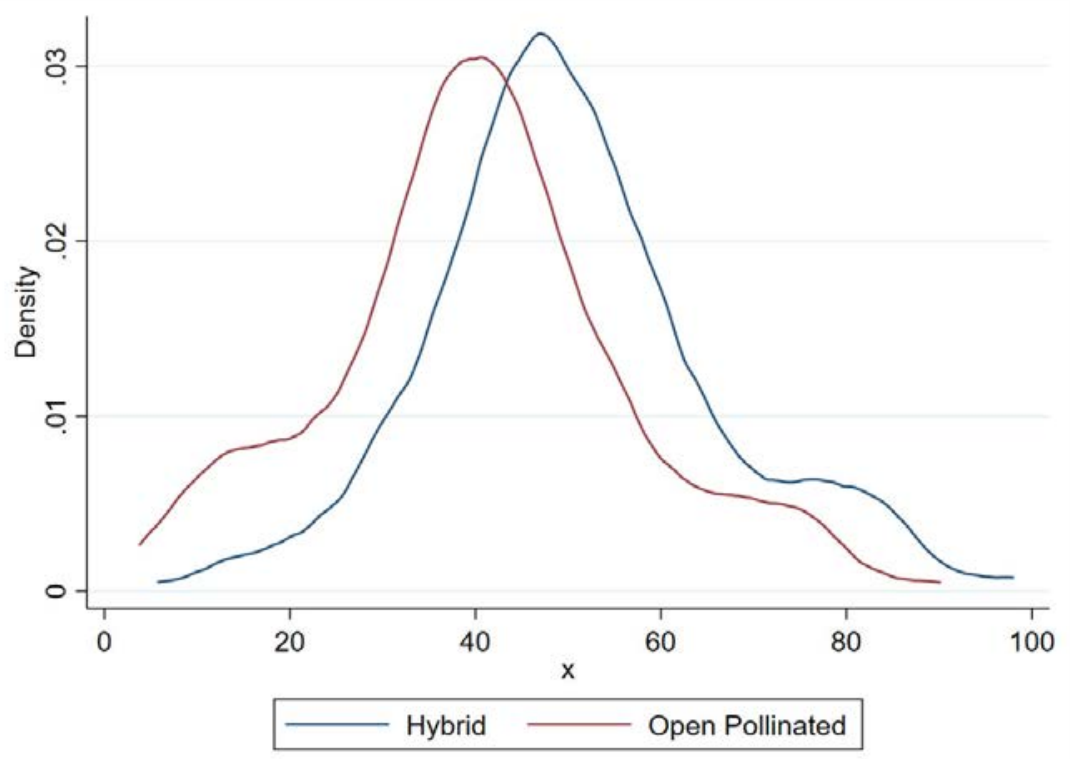

Figure 6. Kernel Density Plots of Hybrid and Open-Pollinated Corn Yields, Various Ranges Between 1937-1941. Source: Authors' tabulation

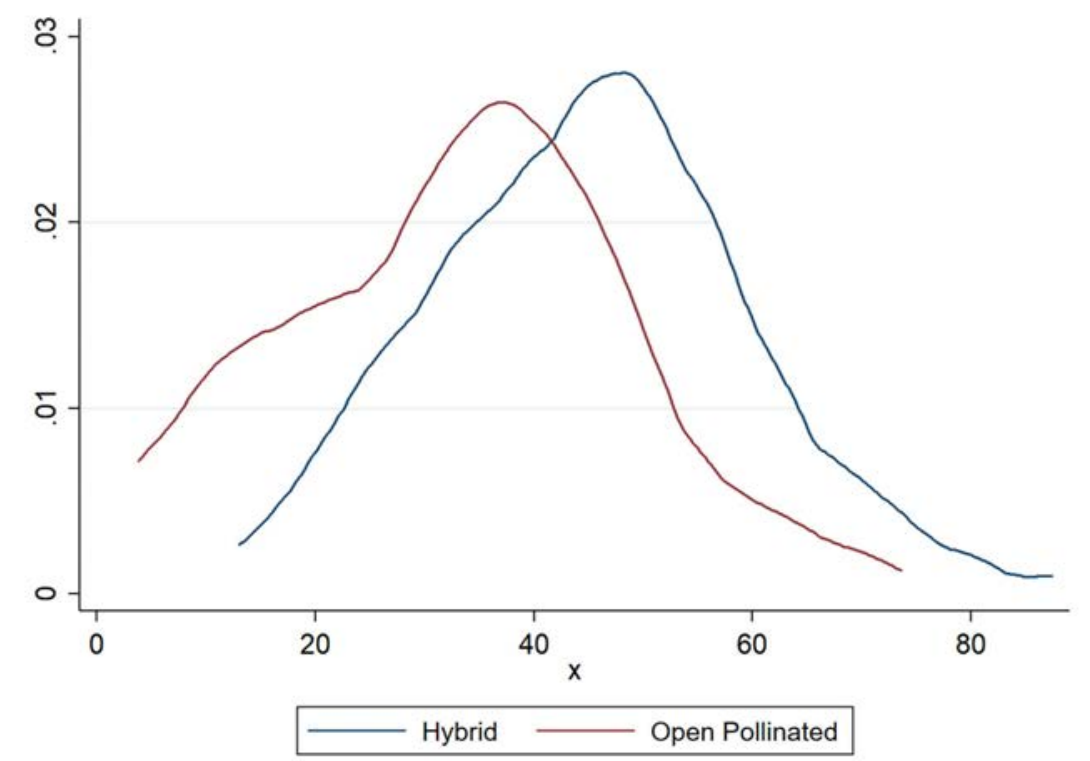

Figure 7. Kernel Density Plots of Hybrid and Open-Pollinated Corn Yields Under Drought Conditions, Various Ranges Between 1937-1941. Source: Authors' tabulation 
Variety Specific Yield and Yield Identical Regressions

The yields of hybrid seed corns and open-pollinated seed corn appears to have a fixed gap on average. The kernel density plots of variety specific yields in Figure 6 suggest that hybrid seeds shifted the yield distribution to the right. Limiting the sample to CRDs experiencing a drought in a year provides a similar pattern. ${ }^{21}$ Figure 7 presents kernel density plots of variety specific yields and the peaks of the distributions are in similar locations to those in Figure 6. The distribution of yields during droughts shifts probability mass towards the left but there does not appear to be a stark contrast between the two figures suggestion drought specific vigor in hybrid seeds relative to open-pollinated seeds. Our regression analysis using yield specific data provides evidence that further suggests that hybrid seeds were not necessarily drought tolerant relative to open-pollinated seeds.

Columns (1), (2), and (3) in Tables 6 report the effects of moderate and extreme drought on hybrid and open-pollinated corn yields. These yields are averages per acre of specific seeds within each CRD. Column (4) reports the effects of temperature and precipitation on yield "identicals," which is the average difference in hybrid and open-pollinated yields for farms where both seed types were grown. The results from columns (1) and (2) suggest that moderate drought did not strongly reduce hybrid or open pollinated yields. Extreme drought decreases both hybrid and open pollinated yields and the effects are significant at the 5\% level and below. Nevertheless, the extreme drought indicator variable does not find a strong statistically significant change in either the yield gap or yield “identical” variables. Table 7 provides an alternative specification where quadratic time trends are replaced with year fixed effects.

Tables 8 and 9 report the relationship between growing degree days and precipitation on the measures of hybrid versus open pollinated performance. In Table 7 the results from columns (1) and

\footnotetext{
${ }^{21}$ We define drought as moderate or worse on the Palmer Drought Severity Index (a value less than -2.)
} 
(2) suggest that corn yields increase for both hybrid and open-pollinated corns under moderate GDD. However, the regression coefficients essentially the same and suggest that 100 additional moderate GDD increase corn yields by approximately $6.7 \%$ (the coefficients are statistically significant at the 1\% level). Column (3) presents some evidence that hybrid corns perform better relative to openpollinated corns. The yield gap between the two hybrid and open-pollinated varieties increases with additional moderate GDD with a 100 unit increase in moderate GDD increasing the yield gap by $0.48 \%$ (this result is statistically significant at the $5 \%$ level when standard errors are clustered at the CRD level). The results for yield “identicals" in column (4) corroborate this result and suggest a 100 unit increase in moderate GDD increase the yield gap by $0.42 \%$ (this result is statistically significant at the $10 \%$ level under both state and CRD clustered errors).

Extreme growing degree days negatively affect both the performance of hybrid and openpollinated corns. According to columns (1) and (2) in Table 8, a 100 unit increase in extreme GDD reduces hybrid corn yields per acre by approximately 51.3\% and reduces open-pollinated corn yields by $66.2 \%$ (both coefficients are statistically significant at the $5 \%$ level). However, there is no statistically significant difference in the gap between the two varieties observed in column (3). According to the yield “identicals” regression in column (4), additional extreme growing degree days reduce the performance of hybrids relative to open-pollinated corns. An additional 100 extreme GDD reduces the yield "identicals" by $30.4 \%$ (this effect is statistically significant at the $5 \%$ and $1 \%$ level depending on clustering). Only in column (4) does total precipitation during the growing season appear to affect the observed difference in hybrid corn and open-pollinated corn yields. In columns (1) through (3) we find no statistically significant relationship between corn yields and changes in precipitation. This gap appears to be increasing in magnitude until total annual precipitation exceeds 68.7 centimeters and rainfall decreases hybrid performance relative to open-pollinated corns once total rainfall exceeds 137.3 centimeters. In Table 9, we present an alternative specification using year 
fixed effects in place of the quadratic time trends. For all specifications this change removes all statistical significance associated with moderate growing degree days. The statistical significance for the negative effect of extreme growing degree days on the yield "identicals" also attenuates. For the hybrid and open pollinated corn yields this specification change does not appear to change yield sensitivity to extreme growing degree days. Using year fixed effects does not substantively change the coefficients or statistical significance of extreme growing degree days in specifications (1) and (2).

\section{Discussion and Conclusion}

If hybrid corns exhibited a unique tolerance toward extreme heat and drought, then we would expect that the difference between hybrid and open-pollinated corn yields to increase in periods of extreme heat. We uncover two distinct patterns in the data regarding hybrid yield performance relative to open-pollinated yield performance. For crop reporting districts in Iowa from 1928 to 1942, extreme temperature increases the yield performance of hybrid seeds relative to open-pollinated seeds. This evidence is consistent with the claims of Richard Sutch and the rural sociologists regarding the drought tolerant nature of hybrids. In Iowa, hybrid corns outperformed their open-pollinated contemporaries. The patterns we uncover are consistent with a scenario where farmers' preferences for drought tolerance drove hybrid adoption.

We find contrasting results using yield data from a later time period and with a broader geographic coverage. Using the yield specific data and the yield “identicals,” we find evidence more consistent with the assessment of Griliches. We do not find strong evidence that extreme temperature increased the performance of hybrid corns relative to open pollinated corns in the years after the Dust Bowl droughts. The evidence from the regression analysis indicates that the difference in yields 
between hybrids and open-pollinated corns increases during moderate GDD. Extreme heat resulting from daily average temperatures in excess of 29 degrees Centigrade do not appear to increase the relative difference in hybrid and open-pollinated corns. Evidence using the yield "identicals" from the unpublished USDA manuscripts indicates that the difference in hybrid and open-pollinated corn yields decreases with additional extreme GDD. This evidence suggests that hybrid corns improved overall yields relative to open-pollinated corns during normal and advantageous growing conditions, but that this increased yield performance attenuates during periods of extreme heat exposure.

On the one hand, our evidence supports Griliches's notion that hybrid seeds increased productivity in corns overall rather than principally during droughts. Such results indicate that the main benefit that hybrid seeds provided in mitigating the adverse effects of extreme temperature come from their overall increase in yields. This increase in yields cushions the adverse effects of drought. On the other hand, evidence from Iowa experimental farms supports the narrative accounts presented by historians and rural sociologists. The nuanced results of this analysis highlight the importance of having appropriate data to address the questions under investigation. 


\section{References}

Crabb, A. R. (1947). The Hybrid-Corn Makers: Prophets of Plenty. Rutgers University Press.

Culver, J. C.; and J. Hyde. (2000). American Dreamer: The Life and Times of Henry A. Wallace. Norton.

David, P. (2003). "Zvi Griliches on Diffusion, Lags and Productivity Growth ... Connecting the Dots."

Dixon, R. (1980). Hybrid corn revisited. Econometrica 48, no. 6, 1451-62.

Dowell, A. A. and O. B. Jesness (1939). Economic aspects of hybrid corn. Journal of Farm Economics 21(2), 479-488.

Fitzgerald, D. (1990). The Business of Breeding: Hybrid Corn in Illinois, 1890-1940. Cornell University Press.

Gilchrist, D. S. and E. G. Sands (2016). Something to talk about: Social spillovers in movie consumption. Journal of Political Economy 124(5), 1339-82.

Griliches, Z. (1957). Hybrid corn: An exploration in the economics of technological change. Econometrica 501-22.

Griliches, Z. (1958). Research costs and social returns: Hybrid corn and related innovations. Journal of Political Economy 66(5), 419-31.

Griliches, Z. (1960). Hybrid corn and the economics of innovation. Science 132(3422), 275-80.

Griliches, Z. (1980). Hybrid corn revisited: a reply. Econometrica 1463-65.

Griliches, Z. papers. Special Collection Library. Harvard University.

Hornbeck, R. (2012) The Enduring Impact of the American Dust Bowl: Short- and Long-Run Adjustments to Environmental Catastrophe. American Economic Review 102 (4): 14771507.

Kloppenburg, J. (1988). First the Seed: The Political Economy of Biotechnology, 1492-2000. Cambridge University Press.

Menne, M.J., I. Durre, R. S. Vose, B. E. Gleason, and T. G. Houston, (2012). An overview of the Global Historical Climatology Network-Daily Database. Journal of Atmospheric and Oceanic Technology 29, 897-910, doi:10.1175/JTECH-D-11-00103.1.

Olmstead, Alan L. and Paul W. Rhode (2008). Creating Abundance: Biological Innovation and American Agricultural Development. Cambridge University Press.

Pioneer Hi-Bred Company papers. Special Collection. Iowa State Univ. Library.

Robinson, J. L., and M. S. Zuber, (1942). The 1941 Iowa corn yield test. Bulletin P, 2(38), 1.

Rogers, Everett (1962). Diffusion of Innovation. New York: Free Press. 
Ryan, B., and N. C. Gross. (1943). The diffusion of hybrid seed corn in two Iowa communities. Rural Sociology, 8(1), 15.

Ryan, B. and N. C. Gross (1950). Acceptance and diffusion of hybrid corn seed in two Iowa communities. Research Bulletin (Iowa Agriculture and Home Economics Experiment Station) 29(372).

Skinner, J., and D. Staiger, (2007). Technological diffusion from hybrid corn to beta blockers. Hardto-Measure Goods and Services: Essays in Honor of Zvi Griliches. University of Chicago Press and NBER.

Schauberger, B., S. Archontoulis, A. Arneth, J. Balkovic, P. Ciais, D. Deryng, ... and T. A. Pugh. (2017). Consistent negative response of US crops to high temperatures in observations and crop models. Nature Communications 8(1), 1-9.

Schlenker, W. and M. J. Roberts (2009). Nonlinear temperature effects indicate severe damages to US crop yields under climate change. Proceedings of the National Academy of Sciences 106(37), 15594-98.

Sutch, R. (2008). "Henry Agard Wallace, the Iowa Corn Yield Tests, and the Adoption of Hybrid Corn.” NBER Working Paper No. 14141.

Sutch, R. (2011). The Impact of the 1936 Corn Belt Drought on American Farmers' Adoption of Hybrid Corn. In Gary Libecap and Richard Steckel, eds, The Economics of Climate Change: Adaptations Past and Present, pp. 195-223. University of Chicago Press.

Urban, N. (1975) "A history of Pioneer's first ten years.” Unpublished memo., Pioneer Hi-Bred Company papers. Special Collections. Iowa State University Library.

USDA. Agricultural Statistics. GPO: Washington, DC.

USDA (1963). Prices paid by farmers for seed: spring season averages, 1926-1961 : September 15 prices, 1949-1961, by states and United States. Statistical Bulletin No. 328. GPO: Washington, DC.

Zuber, M. S., and J. L. Robinson. (1941). The 1940 Iowa corn yield test. Bulletin P, 1(19), 1. 
Table 1. Summary Statistics of Hybrid and Open-Pollinated Yields Sample

\begin{tabular}{llllll}
\hline Variable & Observations & Mean & Std. Dev. & Min & Max \\
\hline Hybrid Yield Per Acre & 211 & 51.430 & 15.069 & 13 & 97.969 \\
Open-Pollinated Yield Per Acre & 211 & 40.669 & 15.854 & 3.8 & 90.092 \\
Yield Difference & 211 & 10.761 & 4.8226 & 2 & 31.700 \\
Moderate Drought, PDSI & 211 & 0.531 & 0.500 & 0 & 1 \\
Extreme Drought, PDSI & 211 & 0.289 & 0.454 & 0 & 1 \\
Moderate Growing Degree Days & 211 & 1773.318 & 228.086 & 1181.853 & 2433.123 \\
Extreme Growing Degree Days & 211 & 60.205 & 29.489 & 12.248 & 146.674 \\
Precipitation & 211 & 0.545 & 0.113 & 0.254 & 0.879 \\
Precipitation squared & 211 & 0.310 & 0.128 & 0.065 & 0.773 \\
Year & 211 & 1939.787 & 1.103 & 1937 & 1941 \\
\hline
\end{tabular}

Table 2. Summary Statistics of Yield Identicals Sample

\begin{tabular}{llllll}
\hline Variable & Observations & Mean & Std. Dev. & Min & Max \\
\hline Yield Identical & 989 & 6.029 & 3.148 & 0.1 & 31 \\
Moderate Drought, PDSI & 989 & 0.568 & 0.500 & 0 & 1 \\
Extreme Drought, PDSI & 989 & 0.267 & 0.442 & 0 & 1 \\
Moderate Growing Degree Days & 989 & 1581.220 & 348.529 & 841.531 & 2433.123 \\
Extreme Growing Degree Days & 989 & 47.621 & 38.649 & 0.721 & 214.064 \\
Precipitation & 989 & 0.547 & 0.160 & 0.197 & 1.233 \\
Precipitation squared & 989 & 0.325 & 0.199 & 0.039 & 1.519 \\
Year & 989 & 1944.219 & 3.876 & 1939 & 1953 \\
\hline
\end{tabular}


Table 3. Summary Statistics of Iowa Experimental Trials Sample

\begin{tabular}{llllll}
\hline Variable & Observations & Mean & Std. Dev. & Min & Max \\
\hline Yield Ratio, Hybrid/Open-Pollinated & 170 & 114.303 & 10.585 & 97.4 & 153.9 \\
Moderate Drought, PDSI & 170 & 0.5 & 0.515 & 0 & 1 \\
Extreme Drought, PDSI & 170 & 0.224 & 0.418 & 0 & 1 \\
Moderate Growing Degree Days & 170 & 1688.860 & 155.203 & 1289.026 & 2091.285 \\
Extreme Growing Degree Days & 170 & 57.457 & 35.310 & 9.589 & 206.420 \\
Precipitation & 170 & 0.567 & 0.088 & 0.394 & 0.841 \\
Precipitation squared & 170 & 0.329 & 0.105 & 0.155 & 0.708 \\
Year & 170 & 1933.565 & 4.740 & 1926 & 1941 \\
\hline
\end{tabular}

Table 4. Drought and Iowa Hybrid and Open-Pollinated Corn Ratios, 1926-1941

\begin{tabular}{lll} 
& $(1)$ & $(2)$ \\
& Iowa Yield Ratio & $\begin{array}{l}\text { Iowa Yield Ratio } \\
\text { Moderate Drought, PDSI }\end{array}$ \\
& 1.22031 & 1.64091 \\
& $(1.32036)$ & $(1.34115)$ \\
Extreme Drought, PDSI & $6.45368^{* * *}$ & $14.31629^{* * *}$ \\
& $(2.16306)$ & $(3.39188)$ \\
\hline CRD Fixed Effects & Yes & Yes \\
Quad. Time Trend & Yes & No \\
Year Fixed Effects & No & Yes \\
Sample & $1926-1941$ & $1926-1941$ \\
$\mathrm{~N}$ & 170 & 170 \\
Adj. $R^{\wedge 2}$ & 0.251 & 0.449 \\
\hline
\end{tabular}

Robust standard errors are in parentheses.

$* \mathrm{p}<0.10 * * \mathrm{p}<0.05 * * * \mathrm{p}<0.01$ 
Table 5. Extreme Heat and Iowa Hybrid and Open-Pollinated Corn Ratios, 1926-1941

\begin{tabular}{|c|c|c|}
\hline & $\begin{array}{l}\text { (1) } \\
\text { Iowa Yield Ratio }\end{array}$ & $\begin{array}{l}\text { (2) } \\
\text { Iowa Yield Ratio }\end{array}$ \\
\hline Moderate GDD, $10^{\circ}-29^{\circ} \mathrm{C}$ & $\begin{array}{l}-0.02343 * * * \\
(0.00867)\end{array}$ & $\begin{array}{l}-0.02925 \\
(0.03604)\end{array}$ \\
\hline Extreme GDD, $>29^{\circ} \mathrm{C}$ & $\begin{array}{l}0.21526 * * * \\
(0.04057)\end{array}$ & $\begin{array}{l}0.41668 * * * \\
(0.09231)\end{array}$ \\
\hline Precipitation, meters & $\begin{array}{l}-12.79066 \\
(65.88781)\end{array}$ & $\begin{array}{l}24.73739 \\
(80.88737)\end{array}$ \\
\hline Precipitation $^{2}$ & $\begin{array}{l}14.94762 \\
(51.77032)\end{array}$ & $\begin{array}{l}-17.50428 \\
(65.28811)\end{array}$ \\
\hline CRD Fixed Effects & Yes & Yes \\
\hline Quad. Time Trend & Yes & No \\
\hline Year Fixed Effects & No & Yes \\
\hline Sample & $1926-1941$ & $1926-1941$ \\
\hline $\mathrm{N}$ & 170 & 170 \\
\hline Adj. $R^{\wedge} 2$ & 0.391 & 0.488 \\
\hline
\end{tabular}

Robust standard errors are in parentheses.

$* \mathrm{p}<0.10 * * \mathrm{p}<0.05 * * * \mathrm{p}<0.01$ 
Table 6. Regression Results, Effect of Palmer Drought Severity Index Drought Measures on Corn Yields, Quadratic Time Trends

\begin{tabular}{lllll} 
& $(1)$ & $(2)$ & $(3)$ & $(4)$ \\
& $\begin{array}{l}\ln (\text { Hybrid } \\
\text { Yield }\end{array}$ & $\begin{array}{l}\ln (\text { Open- } \\
\text { Pollinated Yield }\end{array}$ & $\begin{array}{l}\ln (\text { Yield } \\
\text { Difference) }\end{array}$ & $\begin{array}{l}\ln (\text { Yield } \\
\text { Identical })\end{array}$ \\
& Per Acre $)$ & Per Acre) & & \\
\hline Moderate Drought, PDSI & -0.04312 & -0.03525 & -0.04267 & -0.04166 \\
& $(0.03872)$ & $(0.04083)$ & $(0.06336)$ & $(0.04742)$ \\
& {$[0.02462]^{*}$} & {$[0.02867]$} & {$[0.05517]$} & {$[0.04121]$} \\
Extreme Drought, PDSI & -0.12809 & -0.15996 & -0.05841 & -0.07761 \\
& $(0.04796)^{* *}$ & $(0.07718) *$ & $(0.09487)$ & $(0.03967) *$ \\
& {$[0.03173]^{* * *}$} & {$[0.04594]^{* * *}$} & {$[0.06713]$} & {$[0.05908]$} \\
\hline CRD Fixed Effects & Yes & Yes & Yes & Yes \\
Quad. Time Trend & Yes & Yes & Yes & Yes \\
Sample & $1937-1941$ & $1937-1941$ & $1937-1941$ & $1939-1953$ \\
N & 212 & 212 & 211 & 989 \\
Adj. $R \wedge 2$ & 0.760 & 0.824 & 0.471 & 0.346
\end{tabular}

Standard errors in parentheses are clustered by state. Standard errors clustered by Crop Reporting District are in brackets.

* $\mathrm{p}<0.10 * * \mathrm{p}<0.05 * * * \mathrm{p}<0.01$ 
Table 7. Regression Results, Effect of Palmer Drought Severity Index Drought Measures on Corn Yields, Year Fixed Effects

\begin{tabular}{|c|c|c|c|c|c|}
\hline & \multicolumn{2}{|l|}{ (1) } & \multirow{2}{*}{$\begin{array}{l}(2) \\
\ln (\text { Open- }\end{array}$} & \multirow{2}{*}{$\begin{array}{l}\text { (3) } \\
\ln \text { (Yield }\end{array}$} & \multirow{2}{*}{$\begin{array}{l}(4) \\
\ln \text { (Yield }\end{array}$} \\
\hline & $\ln$ (Hybrid & Yield & & & \\
\hline & Per Acre) & & Pollinated Yield & Difference) & Identical) \\
\hline & & & Per Acre) & & \\
\hline \multirow[t]{3}{*}{ Moderate Drought, PDSI } & -0.02516 & & -0.03045 & 0.01987 & -0.03732 \\
\hline & $(0.03830)$ & & $(0.04180)$ & $(0.06250)$ & $(0.04316)$ \\
\hline & {$[0.02267]$} & & {$[0.02857]$} & {$[0.06014]$} & {$[0.04327]$} \\
\hline \multirow[t]{3}{*}{ Extreme Drought, PDSI } & -0.09129 & & -0.14050 & 0.02762 & -0.06327 \\
\hline & $(0.07218)$ & & $(0.10992)$ & $(0.07857)$ & $(0.05739)$ \\
\hline & {$[0.03849]^{* *}$} & & {$[0.05543]^{* *}$} & {$[0.07215]$} & {$[0.07011]$} \\
\hline CRD Fixed Effects & Yes & & Yes & Yes & Yes \\
\hline Year Fixed Effects & Yes & & Yes & Yes & Yes \\
\hline Sample & $1937-1941$ & & $1937-1941$ & $1937-1941$ & 1939-1953 \\
\hline $\mathrm{N}$ & 212 & & 212 & 211 & 989 \\
\hline Adj. $R^{\wedge} 2$ & 0.771 & & 0.824 & 0.490 & 0.354 \\
\hline
\end{tabular}

Standard errors in parentheses are clustered by state. Standard errors clustered by Crop Reporting District are in brackets.

$* \mathrm{p}<0.10 * * \mathrm{p}<0.05 * * * \mathrm{p}<0.01$ 
Table 8. Regression Results, Effect of Heat Stress on Corn Yields, Quadratic Time Trends

\begin{tabular}{|c|c|c|c|c|}
\hline & (1) & $(2)$ & (3) & (4) \\
\hline & $\ln$ (Hybrid & $\ln ($ Open- & $\ln$ (Yield & $\ln$ (Yield \\
\hline & Per Acre) & Pollinated Yield & Difference) & Identical) \\
\hline & & Per Acre) & & \\
\hline Moderate GDD, $10^{0}-29^{0} \mathrm{C}$ & 0.00065 & 0.00066 & 0.00047 & 0.00041 \\
\hline & $(0.00012) * * *$ & $(0.00017) * * *$ & $(0.00035)$ & $(0.00023)^{*}$ \\
\hline & {$[0.00009] * * *$} & {$[0.00012] * * *$} & {$[0.00021] * *$} & {$[0.00022]^{*}$} \\
\hline Extreme GDD, $>29^{\circ} \mathrm{C}$ & -0.00720 & -0.01086 & 0.00055 & -0.00362 \\
\hline & $(0.00224) * *$ & $(0.00415) * *$ & $(0.00382)$ & $(0.00157)^{* *}$ \\
\hline & {$[0.00154]^{* * *}$} & {$[0.00243]^{* * *}$} & {$[0.00271]$} & {$[0.00136]^{* * *}$} \\
\hline Precipitation, meters & 0.05134 & 1.28623 & 0.52408 & 2.16976 \\
\hline & $(1.49331)$ & $(1.51984)$ & $(2.34221)$ & $(0.78107)^{* *}$ \\
\hline & [1.13843] & [1.34332] & [2.03963] & {$[0.62225]^{* * *}$} \\
\hline Precipitation ${ }^{2}$ & -0.249615 & -1.311283 & -0.750254 & -1.577880 \\
\hline & $(1.22555)$ & $(1.19457)$ & $(2.04302)$ & $(0.49249)^{* * *}$ \\
\hline & {$[0.93803]$} & {$[1.10756]$} & [1.71669] & {$[0.42972]^{* * *}$} \\
\hline CRD Fixed Effects & Yes & Yes & Yes & Yes \\
\hline Quad. Time Trend & Yes & Yes & Yes & Yes \\
\hline Sample & $1937-1941$ & $1937-1941$ & $1937-1941$ & 1939-1953 \\
\hline $\mathrm{N}$ & 212 & 212 & 211 & 989 \\
\hline Adj. $R \wedge 2$ & 0.812 & 0.876 & 0.487 & 0.364 \\
\hline
\end{tabular}

Standard errors in parentheses are clustered by state. Standard errors clustered by Crop Reporting District are in brackets.

$* \mathrm{p}<0.10 * * \mathrm{p}<0.05 * * * \mathrm{p}<0.01$ 
Table 9. Alternative Specification, Regression Results, Effect of Heat Stress on Corn Yields, Year Fixed Effects

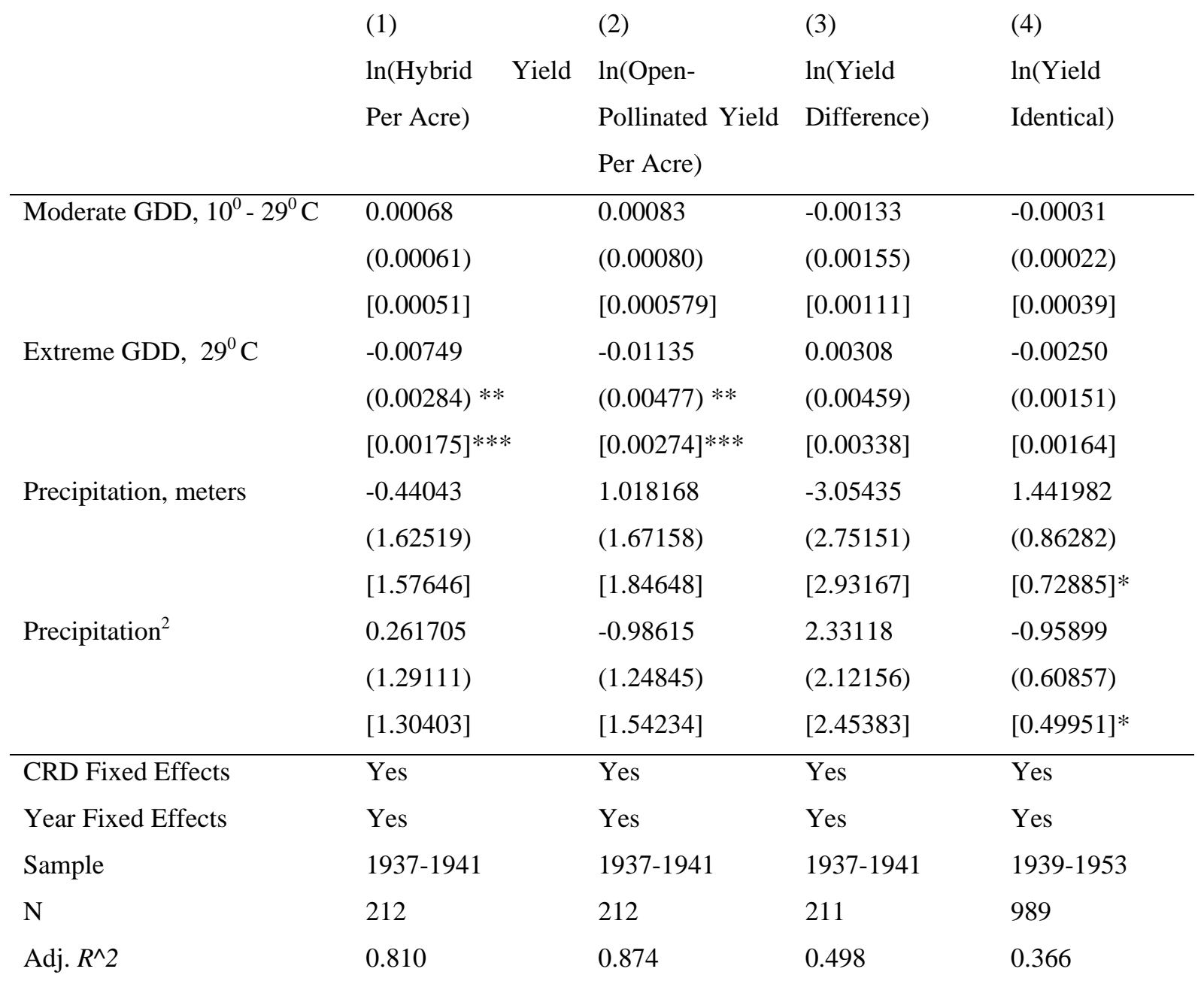

Standard errors in parentheses are clustered by state. Standard errors clustered by Crop Reporting District are in brackets.

$* \mathrm{p}<0.10 * * \mathrm{p}<0.05 * * * \mathrm{p}<0.01$ 


\section{Appendix Figures}

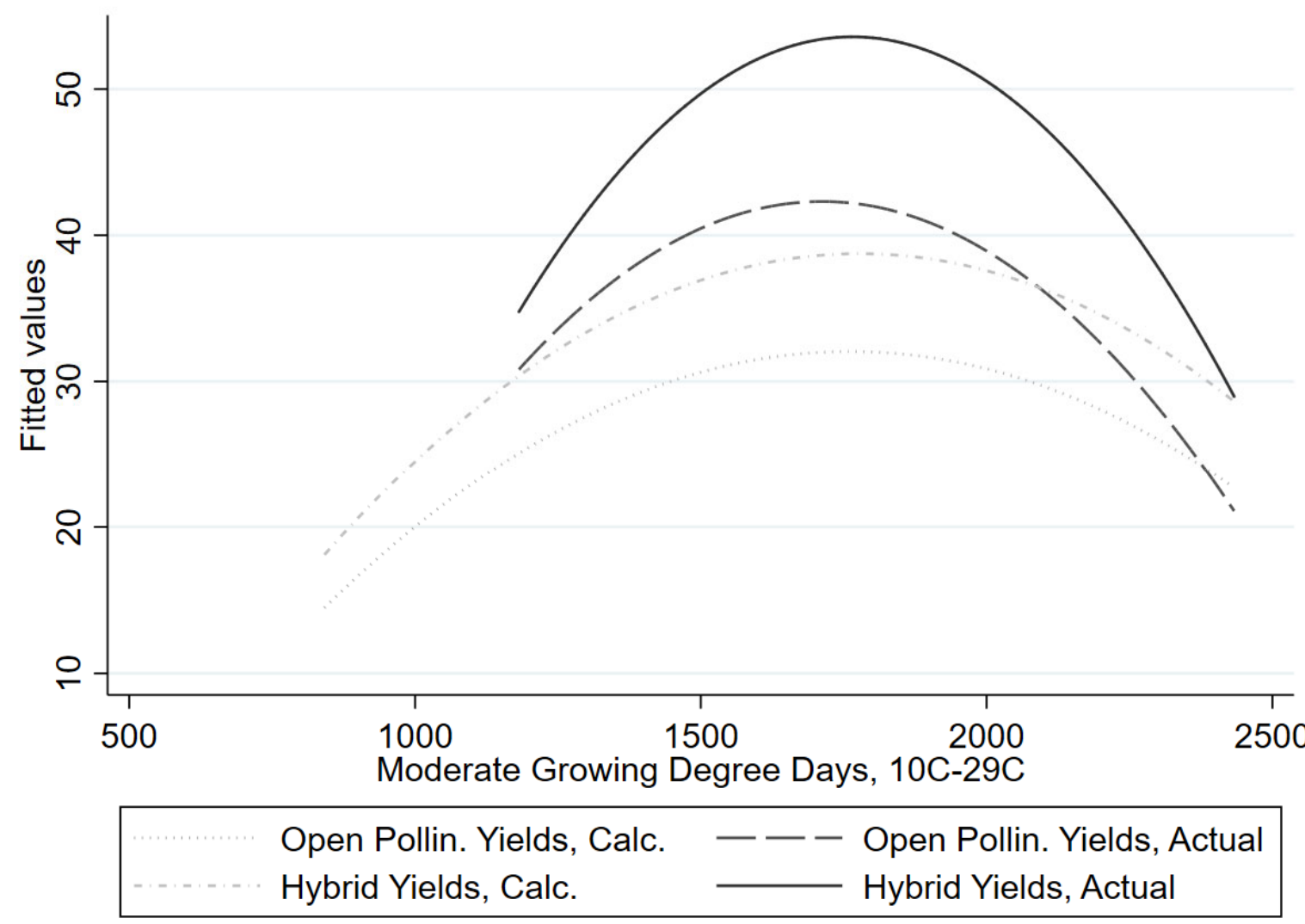

Figure A1. Moderate Growing Degree Days and Fitted Quadratic Lines for Constructed and Actual Hybrid and OpenPollinated Corn Yields. Source: Authors’ Calculations. 


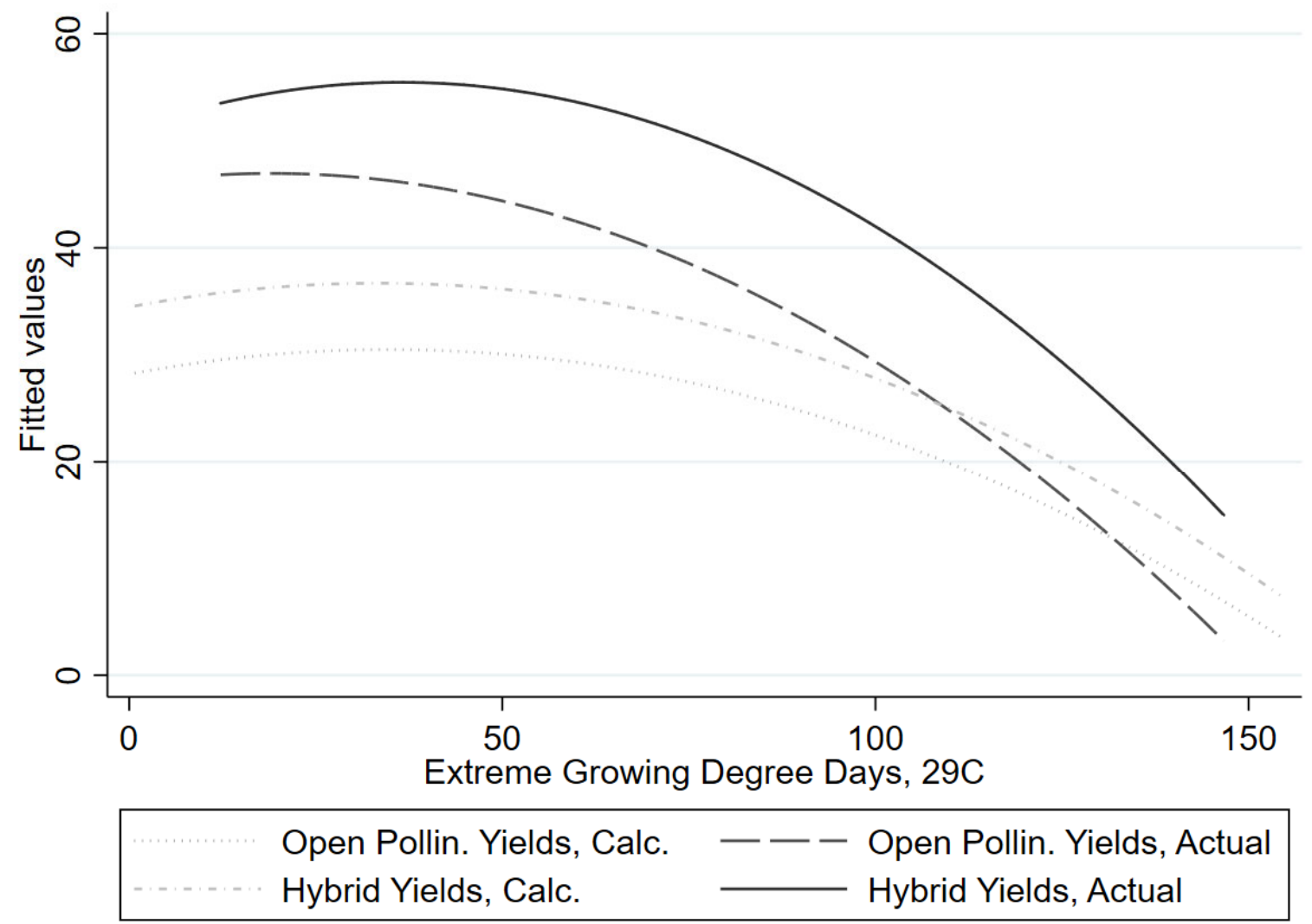

Figure A2. Extreme Growing Degree Days and Fitted Quadratic Lines for Constructed and Actual Hybrid and OpenPollinated Corn Yields. Source: Authors' Calculations.

In Figures A1 and A2, we plot fitted quadric lines to the data to highlight the relationship between moderate and extreme GDD and corn yields. We construct estimated hybrid and open-pollinated corn yields using data on harvested corn acreage and output from the National Agricultural Statistics Service’s Quickstats 2 program, the yield “identical,” and information on share of acreage planted as hybrid corn. ${ }^{22}$ This descriptive evidence suggests that hybrid performance increases more under moderate growing degree days than open-pollinated corns. It also suggests that the difference in yields is either fixed or decreasing in response to extreme growing degree days.

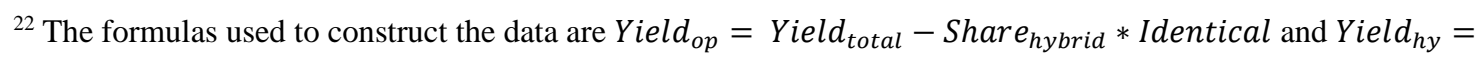
Yield $_{\text {op }}+$ Identical, where Yield $_{\text {total }}$ is the overall average yield in a CRD from Quickstats and Share hybrid $_{\text {is the }}$ fraction of acreage planted as hybrid seed.
} 